\title{
Analisis Penerapan Keselamatan dan Kesehatan Kerja Pada Pekerjaan Struktur Di Proyek Renovasi Gedung Lembaga Penjaminan Mutu Pendidikan (LPMP) Sulawesi Selatan
}

\author{
Marlina Pasarong*1, Junus Mara*2, Helen Adry Irene Sopacua ${ }^{\star 3}$ \\ ${ }^{* 1}$ Mahasiswa Program Studi Teknik Sipil, Universitas Kristen Indonesia Paulus, Makassar \\ Emailmarlinapasarong@gmail.com \\ *2 Dosen Program Studi Teknik Sipil, Universitas Kristen Indonesia Paulus, Makassar \\ Email junus.mara@gmail.com \\ *3 Dosen Program Studi Teknik Sipil, Universitas Kristen Indonesia Paulus, Makassar \\ Emailsspacuahelen2020@gmail.com
}

\begin{abstract}
ABSTRAK
Penerapan Kesehatan dan Keselamatan Kerja (K3) tidak pernah kering dalam konteks samudera keilmuan. Baik dalam sebuah penelitian akademik ataupun dalam kajian praktik. Permasalahan K3 tak henti-hentinya diangkat dalam pembahasan naskah akademik, baik itu jurnal ataupun tugas akhir. Tentu kesemuannya "beririsan" dengan "pisau" yang disebut dengan "penelitian". Dikesempatan ini, yang menjadi fokus peneliti ialah pekerjaan proyek konstruksi di renovasi gedung kantor Lembaga Penjamin Mutu Pendidikan Sulawesi Selatan dengan memakai Metode deskriptif kuantitatif. Yaitu menggambarkan tentang penerapan K3 dan menganalisis kendala dalam penerapan K3 pada proyek tersebut. Untuk menentukan persentase jawaban responden digunakan metode statistika atau dihitung dengan rumus. Hasil penelitian yang telah dilakukan di proyek renovasi gedung Lembaga Penjaminan Mutu Pendidikan (LPMP) Sulawesi Selatan tentang penerapan Keselamatan \& Kesehatan Kerja (K3) terlaksana dengan cukup baik. Adapun kendala pada penerapan Keselamatan \& Kesehatan Kerja ialah kurangnya kesadaran dan pengetahuan pekerja tentang Keselamatan dan Kesehatan Kerja (K3). Selain itu perusahaan juga kurang konsisten dalam menerapkan Keselamatan dan Kesehatan Kerja.
\end{abstract}

Kata kunci: Penerapan, K3, LPMP.

ABSTRACT

The application off occupational health and sahfety (K3) is never dry in the context of the scientific ocean. Either in an academic research or in a practical study. K3 issues are constantly raised in the discussion of academic papers, be it journals or final assignments. Of course, the "intersection" with the "knife" which is called "research". On this occasion, the focus of the researcher was the construction project work in the renovation of the South Sulawesi Education Quality Assurance Institute (LPMP) building using quantitative descriptive methods. Namely describing the application of K3 and analyzing the constrain ts in implementing K3 in the project. Statistical methods are used to determine the percentage of respondents' answers or calculated by formulas. The results off research that hass been carriedt out in the building renovation project off the Education Quality Assurance Institute (LPMP) of South Sulawesi regarding the implementation of Occupational Safety \& Health (K3) are carried out quite well. The obstacle to the implementation of Occupational Safety \& Health is the lack of awareness and knowledge of workers about Occupational Safety and Health (K3). In addition, the company is also less consistent in implementing Occupational Health and Safety.

Keywords: Implementation, K3, LPMP.

\section{PENDAHULUAN}

Keselamatan dan Kesehatan Kerja adalah segala upaya yang dilakukan dalam rangka pencegahan, pengendalian bahaya dalam suatu lingkungan kerja. Depnaker 2012 [1] Kondisi Kesehatan dan Keselamatan Kerja (K3) pada suatu perusahaan dapat menentukan kinerja perusahaan tersebut. Pembangunan Renovasi Gedung Kantor Lembaga Penjaminan Mutu Pendidikan Tahap I Sulawesi Selatan salah satunya. Pada Pembangunan ini, akan dibangun delapan (8) lantai. pekerjaan struktur seperti galian pondasi, pasangan pondasi, 
urungan tanah, urungan pasir, pekerjaan lantai, pekerjaan pembesian kolom, pembesian sloof, pembesian balok, bekesting kolom, bekesting sloof, bekesting balok dan pengecoran bangunan. Kegitatan seperti ini memungkinkan terjadinya kecelakaan kerja dalam pelaksanaan aktivitas perusahaan terutama pada bagian pekerjaan struktur beton bertulang (Asroni 2010). [2]

Fokus penelitian ini pada analisis penerapan K3 pada pekerjaan struktur di proyek renovasi gedung Kantor Lembaga Penjamin Mutu Pendidikan (LPMP) Sulawesi Selatan. Dengan mengacu pada PP Nomor. 50 Tahun 2012 tentang Penerapan Sistem Manajemen Keselamatan dan Kesehatan Kerja.[3]

Tujuan dari penelitian ini adalah untuk mengetahui bagaimana pelaksanaan K3 \& kendala utama pada pekerjaan struktur diproyek Renovasi Gedung LPMP Sulawesi Selatan.

Beberapa penelitian yang pernah dilakukan dan dipublikasikan sebelumnya antara lain: Perfomance Atribut K3 Terhadap Peningkatan Kinerja Karyawan. [4], penerapan K3 di PT Semen Padang. [5], dan Penerapan K3 Pada Proyek Konstruksi Pembangunan Jembatang Dr. Ir. Soekarno di Manado. [6]

\section{METODE}

Pengambilan data berlokasi di Kota Makassar Sulawesi Selatan. Tepatnya di Renovasi Gedung Kantor Lembaga Penjaminan Mutu Pendidikan.

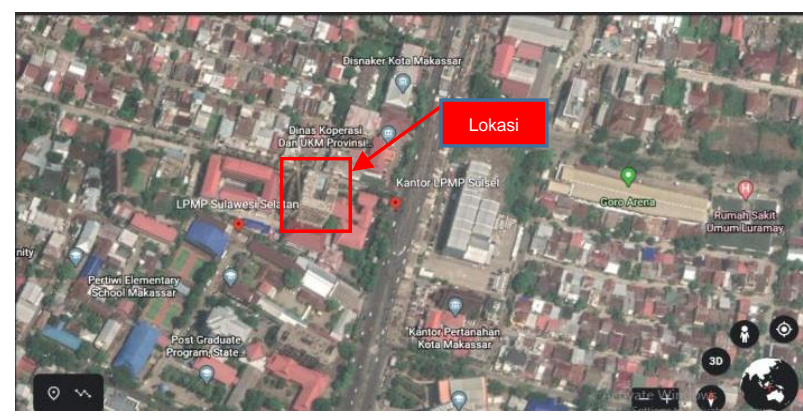

Gambar 1. Peta lokasi pengambilan data

Dalam penelitian digunakan metode deskriptif kuantitatif. [7] Analisis yang dimaksud dalam penelitian ini adalah menggambarkan tentang penerapan $\mathrm{K} 3$ dan menganalisis kendala dalam penerapan K3 pada proyek Renovasi Kantor Lembaga Penjaminanan Mutu Pendidikan (LPMP) Sulawesi Selatan dengan cara kuisioner. Datadata yang diambil secara lengkap selanjutnya akan dilakukan analisis dan diolah dengan standar pedoman kerja Permenaker No. 5/MEN/1996 Tentang Penerapan Sistem Manajemen Keselamatan dan Kesehatan Kerja [8]. Selain itu, PP No. 50 Tahun 2012 Tentang Penerapan K3. Sedangkan dalam penentuan presentase jawaban responden digunakan metode statistika atau dihitung dengan rumus. (Warsito, 2013) [9].

$\mathrm{P}=\frac{m}{n} x 100 \%$

Keterangan:

$\mathrm{P}=$ persentase

$\mathrm{m}=$ jumlah responden yang memilih tingkat pilihan

$\mathrm{n}=$ total jumlah responden

Pengolahan data kuesioner bertujuan untuk mengetahui jawaban tentang pengetahuan responden yang berkaitan dengan penerapan keselamatan dan kesehatan kerja di lapangan. [10] Berdasarkan 7 kritiria dasar yaitu sikap dan komitmen perusahaan, perencanaan, peraturan dan prosedur, pelaksanaan, pengetahuan, tindakan pekerja, lingkungan kerja. sehingga dapat diketahui seberapa besar penerapan dan kendala dari keselamatan dan kesehatan kerja (K3).

Pengambilan data dilakukan dengan menggunakan sampel responden dengan menyebarkan kuisioner dan melibatkan para pekerja yang terlibat didalam proses Renovasi Gedung Kantor Lembaga Penjaminan Mutu Pendidikan (LPMP) Tahap 1 Sulawesi Selatan serta pengamatan langsung di lapangan. Adapun jumlah kuisioner yang disebarkan berjumlah 30 kuisioner

\section{HASIL DAN PEMBAHASAN}




\section{Perhitungan Persentase}

Penerapan kesehatan dan keselamatan Kerja

Tabel 1. Sikap Dan komitmen perusahaan tentang keselamatan dan kesehatan kerja (K3)

\begin{tabular}{|c|c|c|c|c|c|c|c|c|c|c|c|c|c|c|}
\hline \multirow[b]{2}{*}{ No } & \multirow{2}{*}{$\begin{array}{l}\text { Pertanyaan } \\
\text { /Pernyataan }\end{array}$} & \multirow[b]{2}{*}{ SS } & \multirow[b]{2}{*}{$\%$} & \multirow[b]{2}{*}{$\mathrm{S}$} & \multirow[b]{2}{*}{$\%$} & \multirow[b]{2}{*}{$\mathrm{RG}$} & \multirow[b]{2}{*}{$\%$} & \multirow[b]{2}{*}{ TS } & \multirow[b]{2}{*}{$\%$} & \multirow[b]{2}{*}{ STS } & \multirow[b]{2}{*}{$\%$} & \multirow{2}{*}{$\begin{array}{c}\text { Total } \\
(\%)\end{array}$} & \multicolumn{2}{|c|}{ hasil pengamatan langsung } \\
\hline & & & & & & & & & & & & & Diterapkan & $\begin{array}{c}\text { tidak } \\
\text { diterapkan }\end{array}$ \\
\hline 1 & $\begin{array}{l}\text { Perusahaan } \\
\text { melakukan } \\
\text { pemantuan } \\
\text { langsung } \\
\text { terhadap } \\
\text { pelaksanaan } \\
\text { K3 }\end{array}$ & 28 & 93.33 & 2 & 6.6 & 0 & 0 & 0 & 0 & 0 & 0 & 100 & Diterapkan & \\
\hline 2 & $\begin{array}{l}\text { Perusahaan } \\
\text { melakukan } \\
\text { atau } \\
\text { memberikan } \\
\text { breafing } \\
\text { sebelum } \\
\text { memulai } \\
\text { pekerjaan } \\
\text { oleh safety } \\
\text { officer }\end{array}$ & 30 & 100 & 0 & 0 & 0 & 0 & 0 & 0 & 0 & 0 & 100 & & $\begin{array}{c}\text { tidak } \\
\text { diterapkan }\end{array}$ \\
\hline 3 & $\begin{array}{l}\text { Perusahaan } \\
\text { menyediaka } \\
\text { n kotak P3K }\end{array}$ & 30 & 100 & 0 & 0 & 0 & 0 & 0 & 0 & 0 & 0 & 100 & Diterapkan & \\
\hline 4 & $\begin{array}{l}\text { Perusahaan } \\
\text { menyediaka } \\
\text { n APD dan } \\
\text { dibagikan } \\
\text { pada setiap } \\
\text { pekerja }\end{array}$ & 30 & 100 & 0 & 0 & 0 & 0 & 0 & 0 & 0 & 0 & 100 & Diterapkan & \\
\hline 5 & $\begin{array}{l}\text { Perusahaan } \\
\text { memberikan } \\
\text { prioritas } \\
\text { utama } \\
\text { terhadap } \\
\text { masalah } \\
\text { yang terjadi } \\
\text { selama } \\
\text { pelaksanaan } \\
\text { K3 }\end{array}$ & 26 & 86.67 & 4 & 13.3 & 0 & 0 & 0 & 0 & 0 & 0 & 100 & Diterapkan & \\
\hline & Rata-Rata & & 96.00 & & 4.00 & & & & & & & 100 & & \\
\hline
\end{tabular}

Tabel 2. Persentase pelaksanaan keselamatan dan kesehatan kerja (K3)

\begin{tabular}{lllllllllllllll}
\hline & No & $\begin{array}{c}\text { Pertanyaan } \\
\text { Pernyataan }\end{array}$ & SS & $\%$ & S & $\%$ & RG & $\%$ & TS & $\%$ & STS & $\begin{array}{c}\text { Total } \\
(\%)\end{array}$ & $\begin{array}{c}\text { hasil pengamatan } \\
\text { langsung }\end{array}$ \\
\hline 1 & $\begin{array}{l}\text { Pekerja } \\
\text { menggunakan APD }\end{array}$ & 30 & 100 & 2 & 6.67 & 0 & 0 & 0 & 0 & 0 & 0 & 100 & $\begin{array}{c}\text { didak } \\
\text { ditera } \\
\text { diterapkan }\end{array}$ \\
\hline
\end{tabular}


secara benar

2 Menggunakan kecamata pelindung pada spesifikasi pekerjaan 30 $100 \quad 0 \quad 0$

pengelasan pembesian dan pengecoran

3 Menggunakan tali pinggang atau badan bila bekerja 100 pada ketinggian

4 Pekerja dilibatkan langsung dalam investigasi jika terjadi kecelakan

$5 \quad$ Koordinasi yang baik dantra mandor, pekerja dan safety 30 officer

6 Pekerjaan dilakukan sesuai dengan standar SOP untuk menjamin pelaksanaan $\mathrm{K} 3$

$$
\text { Rata-Rata }
$$

Tabel 3. Persentase peraturan dan prosedur keselamatan dan kesehatan kerja (K3)

\begin{tabular}{|c|c|c|c|c|c|c|c|c|c|c|c|c|c|c|}
\hline \multirow{2}{*}{ No } & \multirow{2}{*}{$\begin{array}{l}\text { Pertanyaan } \\
\text { /Pernyataan }\end{array}$} & \multirow{2}{*}{ SS } & \multirow{2}{*}{$\%$} & \multirow{2}{*}{$S$} & \multirow{2}{*}{$\%$} & \multirow{2}{*}{$R G$} & \multirow{2}{*}{$\%$} & \multirow{2}{*}{ TS } & \multirow{2}{*}{$\%$} & \multirow{2}{*}{ STS } & \multirow{2}{*}{$\%$} & \multirow{2}{*}{$\begin{array}{c}\text { Total } \\
(\%)\end{array}$} & \multicolumn{2}{|c|}{$\begin{array}{c}\text { hasil pengamatan } \\
\text { langsung }\end{array}$} \\
\hline & & & & & & & & & & & & & $\begin{array}{c}\text { Diterap } \\
\text { kan }\end{array}$ & $\begin{array}{c}\text { tidak } \\
\text { diterapkan }\end{array}$ \\
\hline 1 & $\begin{array}{l}\text { Peraturan dan } \\
\text { prosedur K3 } \\
\text { dalam } \\
\text { pelaksanaann } \\
\text { ya dapat } \\
\text { diterapkan } \\
\text { dengan } \\
\text { mudah }\end{array}$ & 25 & 83.3 & 2 & 6.6 & 2 & 6.6 & 1 & 3.3 & 0 & 0 & 100 & $\begin{array}{l}\text { Diterap } \\
\text { kan }\end{array}$ & \\
\hline 2 & $\begin{array}{l}\text { Peraturan dan } \\
\text { prosedur K3 } \\
\text { diperbaiki } \\
\text { secara } \\
\text { berkala }\end{array}$ & 30 & 100 & 0 & 0 & 0 & 0 & 0 & 0 & 0 & 0 & 100 & $\begin{array}{l}\text { diterap } \\
\text { kan }\end{array}$ & \\
\hline 3 & $\begin{array}{l}\text { Memberikan } \\
\text { sanksi kepada } \\
\text { pelanggar } \\
\text { peraturan dan } \\
\text { prosedur K3 }\end{array}$ & 22 & 73.3 & 0 & 0 & 0 & 0 & 8 & 26 & 0 & 0 & 100 & $\begin{array}{l}\text { diterap } \\
\text { kan }\end{array}$ & \\
\hline 4 & $\begin{array}{l}\text { Memberikan } \\
\text { sanksi kepada } \\
\text { pelanggar }\end{array}$ & 20 & 66.6 & 3 & 10 & 3 & 10 & 4 & 0 & 0 & 0 & 100 & & $\begin{array}{c}\text { tidak } \\
\text { diterapkan }\end{array}$ \\
\hline
\end{tabular}


peraturan dan

prosedur K3

\begin{tabular}{llllll}
\hline Rata-Rata & 80.8 & 4.1 & 4.1 & 10 & 100 \\
\hline
\end{tabular}

Tabel 4. Persentase perencanaan keselamatan dan kesehatan kerja (K3)

\begin{tabular}{|c|c|c|c|c|c|c|c|c|c|c|c|c|c|c|}
\hline \multirow{2}{*}{ No } & \multirow{2}{*}{$\begin{array}{l}\text { Pertanyaan } \\
\text { /Pernyataan }\end{array}$} & \multirow{2}{*}{ SS } & \multirow{2}{*}{$\%$} & \multirow{2}{*}{$S$} & \multirow{2}{*}{$\%$} & \multirow{2}{*}{$R G$} & \multirow{2}{*}{$\%$} & \multirow{2}{*}{ TS } & \multirow{2}{*}{$\%$} & \multirow{2}{*}{ STS } & \multirow{2}{*}{$\%$} & \multirow{2}{*}{$\begin{array}{l}\text { Total } \\
(\%)\end{array}$} & \multicolumn{2}{|c|}{$\begin{array}{l}\text { hasil pengamatan } \\
\text { langsung }\end{array}$} \\
\hline & & & & & & & & & & & & & $\begin{array}{c}\text { Diterapk } \\
\text { an }\end{array}$ & $\begin{array}{c}\text { tidak } \\
\text { diterapkan }\end{array}$ \\
\hline 1 & $\begin{array}{l}\text { Pada pekerjaan } \\
\text { yang akan } \\
\text { dilaksanakan, } \\
\text { dilakukan } \\
\text { perancanaan } \\
\text { kerja dengan } \\
\text { identifikasi } \\
\text { pengendalian } \\
\text { resiko }\end{array}$ & 30 & 100 & 0 & 0 & 0 & 0 & 0 & 0 & 0 & 0 & 100 & $\begin{array}{l}\text { Diterapk } \\
\text { an }\end{array}$ & \\
\hline 2 & $\begin{array}{l}\text { Mengendalikan } \\
\text { resiko } \\
\text { kecelakaan } \\
\text { dengan } \\
\text { melakukan } \\
\text { perancangan } \\
\text { dan rekayasa }\end{array}$ & 30 & 100 & 0 & 0 & 0 & 0 & 0 & 0 & 0 & 0 & 100 & & $\begin{array}{c}\text { tidak } \\
\text { diterapkan }\end{array}$ \\
\hline 3 & $\begin{array}{l}\text { Mengkonsultasi } \\
\text { kan pada } \\
\text { perwakilan } \\
\text { tenaga kerja } \\
\text { terkait } \\
\text { penetapan dan } \\
\text { tujuan K3 }\end{array}$ & 27 & 90.0 & 0 & 0 & 0 & 0 & 0 & 0 & 0 & 0 & 100 & & $\begin{array}{c}\text { tidak } \\
\text { diterapkan }\end{array}$ \\
\hline 4 & $\begin{array}{l}\text { Prosedur kerja } \\
\text { telah } \\
\text { disosialisasikan } \\
\text { kepada seluruh } \\
\text { pekerja } \\
\text { Pada job }\end{array}$ & 30 & 100 & 3 & 10 & 0 & 0 & 0 & 0 & 0 & 0 & 100 & & $\begin{array}{c}\text { tidak } \\
\text { diterapkan }\end{array}$ \\
\hline 5 & $\begin{array}{l}\text { description } \\
\text { dijelasakan } \\
\text { tanggung jawab } \\
\text { dan wewenang }\end{array}$ & 26 & 86.6 & 2 & 6.6 & 2 & 6 & 0 & 0 & 0 & 0 & 100 & & $\begin{array}{c}\text { tidak } \\
\text { diterapkan }\end{array}$ \\
\hline & Rata-Rata & & 95.3 & & 3.3 & & 1 & & & & & 100 & & \\
\hline
\end{tabular}

Kendala Dalam Penerapan Kesehatan Dan Keselamatan Kerja

Tabel 5. Persentase pengetahuan tentang kesehatan dan keselamatan kerja

\begin{tabular}{llccccccc}
\hline No & Pertanyaan/Pernyataan & $\begin{array}{c}\text { Sangat } \\
\text { Tahu }\end{array}$ & $\%$ & Tahu & $\%$ & $\begin{array}{c}\text { tidak } \\
\text { Tahu }\end{array}$ & $\%$ & Total (\%) \\
\hline $1 \quad \begin{array}{l}\text { Pentingnya pencahayaan } \\
\text { di tempat kerja }\end{array}$ & 22 & 73.33 & 4 & 13.33 & 4 & 13.33 & 100
\end{tabular}


2 Pentingnya ventilasi (sirkulasi udara) yang ditempat kerja

29

96.66

23

76,66

2

6.66

5

16.67

Permanen

4 Banyaknya debu ditempat kerja dapat mengganggu fungsi paru $\begin{array}{lllllll}15 & 50.00 & 5 & 16.67 & 10 & 33.33 & 100\end{array}$
100

100

\section{Rata-Rata}

74.16

9.16

16.66

100

Table .6 Persentase tindakan pekerja tentang kesehatan dan keselamatan kerja

\begin{tabular}{|c|c|c|c|c|c|c|c|c|}
\hline No & Pertanyaan/Pernyataan & Selalu & $\%$ & $\begin{array}{l}\text { Kadang- } \\
\text { Kadang }\end{array}$ & $\%$ & $\begin{array}{c}\text { Tidak } \\
\text { pemah }\end{array}$ & $\%$ & Total (\%) \\
\hline 1 & $\begin{array}{l}\text { Menggunakan APD saat } \\
\text { bekerja }\end{array}$ & 3 & 10.00 & 27 & 90.00 & 0 & 0 & 100 \\
\hline 2 & $\begin{array}{l}\text { Mengikuti peraturan } \mathrm{K} 3 \text { saat } \\
\text { bekerja }\end{array}$ & 6 & 20.00 & 24 & 80.00 & 0 & 0 & 100 \\
\hline 3 & $\begin{array}{l}\text { Kotak P3K digunakan oleh } \\
\text { pekerja }\end{array}$ & 18 & 60.00 & 12 & 40.00 & 0 & 0 & 100 \\
\hline 4 & $\begin{array}{l}\text { Saat bekerja, mengikuti } \\
\text { standar SOP }\end{array}$ & 25 & 83.33 & 5 & 16.67 & 0 & 0 & 100 \\
\hline 5 & $\begin{array}{l}\text { Menggunakanfasilitas } \\
\text { kesehatan yang disediakan }\end{array}$ & 22 & 73.33 & 8 & 26.67 & 0 & 0 & 100 \\
\hline 6 & $\begin{array}{l}\text { Memerhatikan safety sign ( } \\
\text { rambu keselamatan ) } \\
\text { dalambekerja }\end{array}$ & 6 & 20.00 & 24 & 80.00 & 0 & 0 & 100 \\
\hline & Rata-Rata & & 44.44 & & 55.55 & & & 100 \\
\hline
\end{tabular}

Table 7. Persentase tindakan pekerja tentang kesehatan dan keselamatan kerja

$\begin{array}{llllllllllllll}\text { No } & \text { Pertanyaan/Pernyatan } & \text { SS } & \% & \text { S } & \% & \text { RG } & \% & \text { TS } & \% & \text { STS } & \% & \text { Total } & \%\end{array}$

1 Kegeatan pekerjaan didukung dengan tataletak peralatan kerja

$\begin{array}{llllllllll}24 & 80.00 & 3 & 10.00 & 3 & 10 & 0 & 0 & 0 & 0\end{array}$

dan mesin

2 Tersedianya informasi peta dan lokasi menuju jalur evakuasi

100

3 Kondisi pencahayaan yang baik dalam mempermudah

melakukan pekerjaan

4 Suhu udara yang baik mendukung

$\begin{array}{lll}90.00 & 12.5 & 2.5\end{array}$

0

0

0

90.00

0




\section{a. Penerapan Kesehatan dan Keselamatan Kerja (K3)}

Pembahasan dalam penerapan K3 di terdiri diri 30 responden yang memberikan jawaban dengan mengisi kuisioner yang disebar secara langsung.

Berdasarkan pengamatan pada bagian sikap dan komitmen perusahaan tentang Kesalamatan dan Kesehatan Kerja (K3), perusahaan telah melakukan pemantauan langsung terhadap pelaksanaan K3, perusahaan juga telah menyediakan kotak P3K dan menyediakan APD yang dibagikan pada setiap pekerja. Namun perusahaan tidak memberikan breafing sebelum memulai pekerjaan oleh Safety Office.

Pada bagian pelaksanaan keselamatan dan kesehatan kerja (K3), dari hasil pengamatan langsung, pekerja telah menggunakan APD secara benar, telah menggunakan kacamata pelindung pada spesifikasi pekerjaan pengelasan pembesian dan pengecoran, telah menggunakan tali pinggang atau badan bila bekerja pada ketinggian, telah melibatkan pekerja secara langsung dalam investigasi jika terjadi kecelakaan, telah menerapkan koordinasi yang baik antara mandor, pekerja dan safety officer dan telah melakukan pekerjaan sesuai dengan standar SOP untuk menjamin pelaksanaan K3. Dari keseluruhannya pada bagian ini perusahaan telah menerapkan Pelaksanaan Keselamatan dan Kesehatan Kerja (K3) dengan baik.

Berdasarkan pengamatan langsung pada bagian peraturan dan prosedur $\mathrm{K} 3$, perusahaan telah menerapkan peraturan dan prosedur $\mathrm{K} 3$ yang dapat diterapkan dengan mudah, perusahaan juga telah menerapkan perbaikan peraturan dan prosedur K3 secara berkala, perusahaan juga telah menerapkan sanksi bagi pekerja yang melaggar peraturan dan prosedur K3. Namun perusahaan kurang konsisten dalam pelaksanaan peraturan dan prosedur K3.

Berdasarkan pengamatan langsung pada bagian perencanaan Keselamatan dan Kesehatan Kerja (K3), perusahaan telah melakukan perencanaan kerja dengan mempertimbangkan risiko pada kegiatan yang akan dilakukan. Pada poin kedua, perusahaan tidak melakukan perancangan dan rekayasa untuk mengendalikan risiko kecelakaan dan penyakit akibat kerja. Point ketiga perusahaan juga tidak menerapkan penetapan tujuan dan sasaran K3 yang seharusnya dikonsultasikan pada wakil tenaga kerja. Begitupun pada poin ke empat, perusahaan tidak melakukan sosialisasi kepada seluruh pekerja mengenai prosedur kerja. Sedangkan pada poin kelima perusahaan telah menerapkan tanggung jawab dan wewenang dijelaskan pada job description masing-masing.

Adapun nilai rata-rata yang diperoleh berdasarkan kuisioner dan pengamatan langsung pada penelitian diatas, dapat disimpulkan bahwa pelaksanaan Keselamatan \& Kesehatan Kerja di Proyek Renovasi Kantor Lembaga Penjaminan Mutu Pendidikan (LPMP) Sulawesi Selatan terlaksana cukup baik.

\section{b. Kendala Keselamatan dan Kesehatan Kerja (K3)}

Untuk bagian kendala (penerapan) K3 darii 30 responden yang memberikan jawaban dengan mengisi kuisioner yang disebar secara langsung.

Pengetahuan faktor pada bagian pengetahuan persentasenya mencapai $74.16 \%$ untuk responden yang sangat tahu. Sedangkan untuk responden yang tahu $9.16 \%$. adapun yang responden yang tidak mengetahui tentang prosedur K3 mencapai $16.66 \%$.

Tindakan pekerja Pada faktor ini responden yang selalu bekerja sesuai dengan standar K3 mencapai persentase $44.44 \%$. sedangkan responden yang kadang-kadang sesuai dengan standar K3 mencapai 55.55\%.

Lingkungan kerja faktor pada bagian lingkungan kerja mencapai persentase $85.00 \%$. responden setuju sesuai dengan lingkungan kerja mencapai $12.5 \%$. sedangkan untuk responden yang raguragu terhadap lingkungan kerja mencapai $2.5 \%$.

\section{KESIMPULAN}

Penerapan program Keselamatan dan Kesehatan Kerja di Proyek Renovasi Kantor Lembaga Penjaminan Mutu Pendidikan (LPMP) Sulawesi Selatan terlaksana dengan cukup baik.

Adapun kendala pada penerapan keselamatan dan Kesehatan Kerja ialah minimnya kesedaran dan pengetahuan K3. Selain itu perusahaan juga 
kurang konsisten dalam menerapkan Keselamatan dan Kesehatan Kerja.

\section{DAFTAR PUSTAKA}

[1] Departemen Ketenagakerjaan RI, 2012, Sistem Manajemen Keselamatan dan Kesehatan Kerja, Jakarta.

[2] Asroni Ali, 2010, Kolom, Fondasi, dan Balok ' $T$ ' Betong Bertulang, Graha IImu, Yogayakarta.

[3] Peraturan Pmerintah No.50 Tahun 2012, Sistem Manajemen Keselamatan dan Kesehatan Kerja.

[4] Munir, 2014, Perfomance Atribut K3 Terhadap Peningkatan Kinerja Karyawan, Skripsi, Universitas Jember, Jember.

[5] Herlina, 2016, Penerapan K3 di PT Semen Padang, Skripsi, Universitas Andalas, Padang.
[6] Pangkey, 2012, Penerapan K3 Pada Proyek Kontruksi Pembangunan Jembatan Dr. Ir. Soekamo di Manado, Skripsi, Universitas Samratulangit, Manado.

[7] Husein, 2013, Metodologi penelitian untuk skripsi dan Tesis, PT.Gramedia Pustaka, Jakarta.

[8] Peraturan Menteri Tenaga Kerja Nomor : PER.05/MEN/1996 Tentang Sistem Manajemen Keselamatan dan Kesehatan Kerja.

[9] Warsito, 2012, Pengantar Metodologi Penelitian : Buku Panduan Mahasiswa, Gramedia Puustaka Utama, Jakarta.

[10] Martonno, Nannang, 2011, Metode Penelitian Kuantitatif, PT Raya Gerafindo Perssada, Jakarta. 